\title{
Long-Term Depression and Depotentiation in the Sensorimotor Cortex of the Freely Moving Rat
}

\author{
David J. Froc, C. Andrew Chapman, Christopher Trepel, and Ronald J. Racine \\ Department of Psychology, McMaster University, Hamilton, Ontario L8S 4K1, Canada
}

Activity-dependent reductions in synaptic efficacy are central components of recent models of cortical learning and memory. Here, we have examined long-term synaptic depression (LTD) and the reversal of long-term potentiation (depotentiation) of field potentials evoked in sensorimotor cortex by stimulation of the white matter in the adult, freely moving rat. Prolonged, low-frequency stimulation ( $1 \mathrm{~Hz}$ for $15 \mathrm{~min}$ ) was used to induce either depotentiation or LTD. LTD was expressed as a reduction in the amplitude of both monosynaptic and polysynaptic field potential components. Both LTD and depotentiation were reliably induced by stimulation of the ipsilateral white matter. Stimulation of the contralateral neocortex induced only a depotentiation effect, which decayed more rapidly than that in- duced by ipsilateral stimulation (hours vs days). Although ipsilateral LTD was effectively induced by a single session of lowfrequency stimulation, multiple sessions of stimulation, either massed or spaced, induced LTD effects that were larger in magnitude and longer lasting. Previously, we showed that the induction of long-term potentiation in the neocortex of chronic preparations required multiple, spaced stimulation sessions to reach asymptotic levels. Here, we report that LTD also required multiple stimulation sessions to reach asymptotic levels, but massed and spaced patterns of low-frequency stimulation were equally effective.

Key words: neocortex; long-term potentiation; LTP; LTD; plasticity; memory
Various neural network models incorporate rules for the bidirectional modification of synaptic weights that are based on variations of the "Hebb synapse" (Hebb, 1949). These bidirectional learning rules specify that connection weights will be increased or decreased depending on whether the presynaptic and postsynaptic activity is correlated or uncorrelated, respectively (Brown et al., 1990). Such rules prevent the saturation of enhanced connection weights and maintain the capacity of the circuit to store new information.

The implementation of bidirectional learning rules in real neuronal circuits requires mechanisms that support both increases and reductions in synaptic strength. Experimentally, increases in synaptic strength can be induced by brief, highfrequency stimulation of afferent pathways, whereas prolonged low-frequency stimulation leads to reductions in synaptic drive. These phenomena are referred to as long-term potentiation and long-term depression (LTD). Depression of potentiated responses is referred to as depotentiation.

Long-term synaptic potentiation (LTP) is currently the most widely investigated model of the synaptic mechanisms underlying memory formation in the mammalian brain (Bliss and Lomo, 1973; Tsumoto, 1992; Bliss and Collingridge, 1993). Although it can be reliably induced in the hippocampus in slice, acute, and chronic preparations, it has often been difficult to induce in the

\footnotetext{
Received June 18, 1999; revised Sept. 3, 1999; accepted Sept. 28, 1999.

This research was supported by a grant from the Canadian Natural Sciences and Engineering Research Council.

Correspondence should be addressed to R. J. Racine, Department of Psychology, McMaster University, Hamilton, Ontario L8S 4K1, Canada. E-mail: racine@mcmaster.ca.

Dr. Trepel's present address: Department of Physiology, University of California, Box 0444, 513 Parnassus Avenue, University of California at San Francisco, San Francisco, CA 94143-444.

Dr. Chapman's present address: Department of Psychology, Concordia University, Montreal, Quebec, Canada.

Copyright (C) 1999 Society for Neuroscience $\quad 0270-6474 / 99 / 190438-08 \$ 15.00 / 0$
}

neocortex, particularly in the awake, freely moving rat (Racine et al., 1995; Beiko and Cain, 1998; Trepel and Racine, 1998). Neocortical LTP induction in the awake animal requires that the stimulation be spaced and repeated. Unlike hippocampal LTP, which can reach asymptotic levels in one stimulation session, stimulation of the white matter must be distributed over 7-12 d to maximize LTP in sensorimotor cortex (Trepel and Racine, 1998). Using this paradigm, neocortical LTP is as reliable as hippocampal LTP.

The literature is not entirely consistent, however, regarding the induction of LTD and depotentiation, at least in the hippocampus. Stimulation protocols that successfully induced LTD and depotentiation in the dentate gyrus in vitro were ineffective in vivo (Errington et al., 1995; Abraham et al., 1996). In the freely moving rat, prolonged low-frequency stimulation of hippocampal area CA1 has been reported to produce a number of outcomes, including reliable LTD (Manahan-Vaughan, 1997), depotentiation but no LTD (Staubli and Lynch, 1990; Doyle et al., 1997), or neither depotentiation nor LTD (Errington et al., 1995). Both LTD (Thiels et al., 1994; Heynen et al., 1996) and depotentiation (Heynen et al., 1996) have been successfully induced in area CA1 in the anesthetized in vivo preparation. Staubli and Scafidi (1997), on the other hand, were unable to induce LTD in this preparation using similar patterns of stimulation, and Barrionuevo et al. (1980) could only induce depotentiation.

The few demonstrations of LTD or depotentiation in the neocortex have been conducted in slice (Kirkwood and Bear, 1994b; Castro-Alamancos et al., 1995) or anesthetized (Tsumoto and Suda, 1979; Burette et al., 1997) preparations. In this paper, we demonstrate reliable long-term depression and depotentiation of field potentials recorded from the sensorimotor cortex of the chronically prepared rat. The use of this preparation also allowed us to confirm that the LTD and depotentiation effects were long lasting and to examine some of the stimulation parameters that 
affect the longevity of these effects. Because LTP induction in this preparation requires repeated daily sessions of stimulation (Racine et al., 1995; Trepel and Racine, 1998), we also tested for differences in LTD induced by single or multiple stimulation sessions.

Parts of this paper have been presented in abstract form (Froc and Racine, 1995; Froc et al., 1996).

\section{MATERIALS AND METHODS}

\section{Animals and surgery}

Fifty-four male Long-Evans rats (300-400 gm) from the McMaster University Breeding Colonies were used in these experiments. Rats were anesthetized with Somnotol (sodium pentobarbital, $65 \mathrm{mg} / \mathrm{kg}$ i.p.) and received atropine $(1.2 \mathrm{mg} / \mathrm{kg})$ to prevent respiratory distress. Twisted wire bipolar electrodes were constructed from Teflon-coated stainless steel wire (120 $\mu \mathrm{m}$ diameter), and the exposed tips were separated by 1.0 $\mathrm{mm}$ for cortical placements and $0.5 \mathrm{~mm}$ for the callosal stimulating electrodes. Electrodes were implanted into either the sensorimotor cortex (M1 bordering on S1) or the white matter in the same coronal plane. Sensorimotor cortex electrodes were placed $2.0 \mathrm{~mm}$ anterior to bregma and 3.5 or $4.0 \mathrm{~mm}$ lateral to the midline at a depth of $2.0 \mathrm{~mm}$ from pia (Paxinos and Watson, 1997). White matter electrodes were placed 2.0 $\mathrm{mm}$ anterior to bregma, $2.0 \mathrm{~mm}$ lateral to the midline, at a depth of 3.0 $\mathrm{mm}$ from pia. Electrode depths were adjusted during surgery to maximize field response amplitudes. The electrodes were connected to goldplated pins and inserted into a connector plug that was anchored to the skull surface with dental cement and four stainless steel screws. One screw in the right occipital bone served as a ground electrode.

In this preparation, the electrode resistance is always $\sim 20 \mathrm{~K} \Omega$. To verify that the low-frequency stimulation parameters used in the following experiments did not change the resistance, we monitored resistance in both stimulating and recording electrodes in three animals before and after multiple sessions of stimulation. The resistances were 19.32, 19.05, and $20.64 \mathrm{~K} \Omega$ for the stimulating electrodes and 20.91, 21.09, and 23.44 $\mathrm{K} \Omega$ for the recording electrodes (measured at $250 \mu \mathrm{A}$ ). These resistances did not change after three sessions of low-frequency stimulation (which reliably produced a long-term depression effect).

Rats were housed individually on a $12 \mathrm{hr}$ light/dark cycle and tested during the light cycle. A 2 week recovery period preceded experimental testing.

\section{Stimulation and recording}

Input-output tests. During input-output (I-O) tests, stimulation pulses were delivered at varying intensities to the appropriate stimulation site (see below), and evoked field potentials were monitored in the cortex. Single $0.1 \mathrm{msec}$ biphasic square wave pulses were delivered through constant current isolation units at a frequency of $0.1 \mathrm{~Hz}$. The I-O test included eight responses evoked at each of 10 logarithmically spaced intensities $(16,32,64,100,160,250,500,795,1000$, and $1260 \mu \mathrm{A})$. The responses were filtered $(0.3 \mathrm{~Hz}$ to $3 \mathrm{kHz})$, amplified, digitized at $10 \mathrm{kHz}$, and stored on a computer hard drive. Two or three baseline I-O tests, separated by $48 \mathrm{hr}$, were used to confirm the stability of the evoked responses.

For each experiment, animals were divided into experimental and control groups that were matched for response morphology, amplitude, and threshold. Control groups did not receive train stimulation, but otherwise followed the same regimen as experimental groups.

Long-term potentiation. In experiments requiring LTP induction, 30 high-frequency trains were delivered once per day for $10 \mathrm{~d}$. Each $24 \mathrm{msec}$ train consisted of 8 pulses at $300 \mathrm{~Hz}$, and the trains were delivered once every $10 \mathrm{sec}$. Pulse intensity was $1260 \mu \mathrm{A}$, and the pulse duration was 0.1 msec. Paper records of EEG activity were monitored to confirm that epileptiform discharges were not evoked. Input-output tests were recorded 1 and $7 \mathrm{~d}$ after the LTP induction procedure to confirm that the potentiation effects were long-lasting.

Long-term depression and depotentiation. To induce long-term depression, low-frequency stimulation $(1 \mathrm{~Hz}, 900$ pulses, $1260 \mu \mathrm{A})$ was delivered immediately after the last baseline $\mathrm{I}-\mathrm{O}$ test. To examine depotentiation, the low-frequency stimulation was delivered 8 days after LTP induction. Input-output tests were recorded immediately, 1, 2, and $7 \mathrm{~d}$ after low-frequency trains to determine the longevity of the effects.

\section{Design}

There were three experiments. The first dealt with both depotentiation and LTD effects produced by stimulation of the contralateral homologous site. The second experiment compared depotentiation effects produced by ipsilateral and contralateral stimulation. The third experiment dealt with LTD induced by ipsilateral white matter stimulation.

Depotentiation and LTD of the interhemispheric response. The first experiment examined whether LTP induced in the right sensorimotor cortex by tetanization of the left motor cortex could be reversed or depotentiated by low-frequency stimulation. In addition, low-frequency stimulation applied to unpotentiated animals provided a test for LTD.

Twenty four hours after the second baseline I-O test, LTP was induced in nine animals by $10 \mathrm{~d}$ of high-frequency stimulation. The high-frequency stimulation was applied directly to the left sensorimotor cortex. An additional eight animals served as unpotentiated controls. Responses were recorded in the homologous site in the right hemisphere. I-O tests were recorded 1 and $7 \mathrm{~d}$ after LTP induction to confirm that the potentiation effects were truly long-lasting. Five of the potentiated animals were then tested for depotentiation, whereas four of the animals remained unstimulated to confirm that the potentiation was maintained in the absence of low-frequency stimulation. Similarly, four of the unpotentiated control animals received low-frequency stimulation to test for LTD effects in the contralateral field potential. The remaining four control animals served to ensure that the baseline responses remained stable. I-O tests were recorded immediately and 1,2 , and $7 \mathrm{~d}$ after delivery of low-frequency trains to determine the longevity of the depotentiation and LTD effects.

Depotentiation of ipsilateral versus contralateral responses. The transhemispheric depotentiation effects in the previous experiment were found to be reliable, but short-lived. In this experiment, the longevity of depotentiation induced by contralateral stimulation was compared to depotentiation induced by ipsilateral stimulation. Recording electrodes were implanted into the right sensorimotor cortex in all animals. Stimulating electrodes were implanted into either the contralateral homologous site $(n=7)$ or into the ipsilateral white matter $(n=6)$. After three baseline I-O tests, high-frequency trains were used to induce LTP in all animals. Seven days after LTP induction, low-frequency trains were delivered, and the extent of depotentiation induced in the contralateral and ipsilateral stimulation groups was compared. To monitor the early phase of the decay of depotentiation, I-O tests were recorded immediately after the low-frequency stimulation, hourly for $6 \mathrm{hr}$, and after 8,10 and $12 \mathrm{hr}$. Follow-up I-Os were also collected 24 and $48 \mathrm{hr}$ after treatment.

Long-term depression. In the final experiment, LTD of field responses evoked by stimulation of the ipsilateral white matter was examined, and LTD effects induced by either single or multiple low-frequency trains were compared. Furthermore, the effect of spacing the trains over time was also assessed. Stimulating electrodes were implanted into the white matter of the right hemisphere, and recording electrodes were placed ipsilaterally into sensorimotor cortex. After three baseline I-O tests, the animals were divided into three experimental groups (single-train, $n=6$; massed-trains, $n=6$; spaced-trains, $n=6$; and one control group, $n=6$ ). Animals in the single-train group received one low-frequency train, whereas animals in the multiple-train groups received 10 trains. The massed-trains group received 10 trains on a single day at hourly intervals. The spaced-trains group received one train per day for $10 \mathrm{~d}$.

In the single-train group, I-O recordings were taken immediately, 1, 2, 4,8 , and $12 \mathrm{hr}$ after the low-frequency train to monitor the early phase of LTD decay. In the massed-trains group, I-O tests were recorded after each train, and in the spaced-trains group, I-O tests were recorded before and after each train. In all groups, I-O recordings were taken every day for $7 \mathrm{~d}$ and weekly for 2 weeks after the last low-frequency train.

\section{Data analysis}

Changes in the field potentials over LTD (or LTP) and decay sessions were measured by subtracting the final baseline responses from all other baseline and depressed (or potentiated) responses. All data points were thus standardized to the final baseline response. For depotentiation experiments, changes were assessed relative to the last post-LTP I-O test. Measures (millivolts of change from baseline) were taken at two latencies representing the early, monosynaptic, and late, polysynaptic, components (Chapman et al., 1998). Changes in response amplitudes (in millivolts) were analyzed using mixed design ANOVAs and the Tukey honestly significant difference (HSD) post hoc test. The changes are 


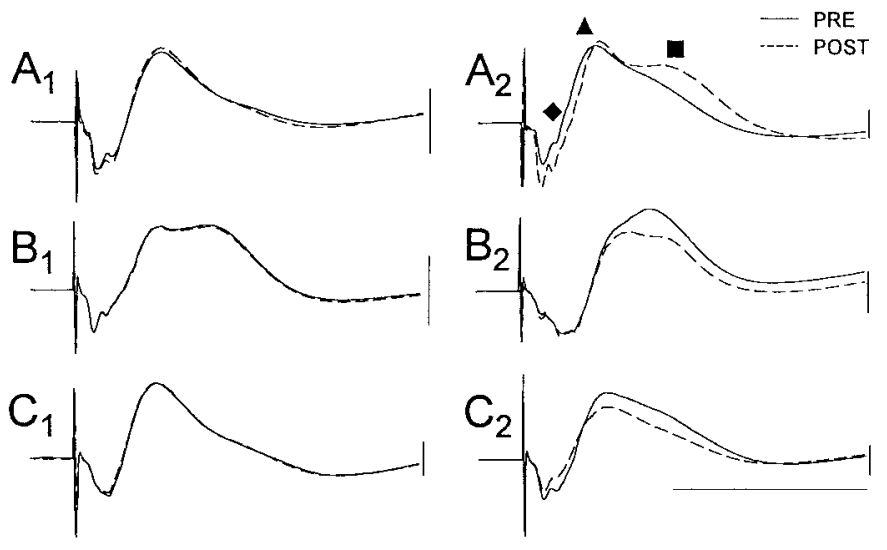

Figure 1. Changes in field potential amplitude evoked in the right sensorimotor cortex by high- and low-frequency stimulation of the homologous contralateral site. Representative field responses are shown for both a control and a potentiated animal $\left(A_{1}\right.$ and $\left.A_{2}\right)$, a potentiated and depotentiated animal $\left(\mathrm{B}_{1}\right.$ and $\left.B_{2}\right)$, and a control and LTD animal $\left(\mathrm{C}_{1}\right.$ and $C_{2}$ ). The solid lines represent prestimulation responses, and the dashed lines represent the response after conditioning stimulation had been delivered to the experimental animals. $A$, High-frequency stimulation caused an enhancement in the repetitive population spike activity $(\bullet)$ associated with an apparent reduction in the amplitude of the early monosynaptic component $(\boldsymbol{\Delta})$ and the enhancement of a longer latency polysynaptic component (⿷). $B, C$, Depotentiation and LTD of field responses evoked in the sensorimotor cortex. Although potentiated $\left(B_{1}\right)$ and control $\left(\mathrm{C}_{1}\right)$ responses remain stable in the absence of low-frequency stimulation, depotentiation $\left(\mathrm{B}_{2}\right)$ and LTD $\left(\mathrm{C}_{2}\right)$ of the late component are induced by the delivery of a single low-frequency $(1 \mathrm{~Hz}, 15 \mathrm{~min})$ train. Stimulation intensity was $795 \mu \mathrm{A}$. Calibration: $1 \mathrm{mV}, 25 \mathrm{msec}$.

expressed as percentage of baseline amplitude (group means) evoked at low to midrange intensities (see below).

\section{Histology}

Rats were deeply anesthetized with urethane $(2.0 \mathrm{gm} / \mathrm{kg})$ and perfused through the heart with formol-saline. Frozen brain sections were cut at 40 $\mu \mathrm{m}$ and stained with cresyl violet to verify electrode placements.

\section{RESULTS}

Histological examination confirmed that the electrode tips were in their intended targets for all animals. The M1 field potentials were as characterized by Chapman et al. (1998). Both contralateral and ipsilateral responses showed overlapping monosynaptic EPSP and population spike components. The population spikes tended to be small, began at $\sim 3 \mathrm{msec}$, and repeated over 9-33 msec. The polysynaptic component peaked at $\sim 18.0 \mathrm{msec}$ for contralateral responses and $19.5 \mathrm{msec}$ for ipsilateral responses. Ipsilateral responses often contained a broader and more complex waveform, compared to the contralateral response, which may account for the slightly longer latency to peak.

\section{Depotentiation of interhemispheric responses Long-term potentiation}

Representative responses evoked in the right sensorimotor cortex by stimulation of the homologous site in the left hemisphere are shown in Figure 1. LTP induction was characterized by an increase in the repetitive population spike activity (which masks the enhancement of the early monosynaptic EPSP) and a potentiation of the longer latency, polysynaptic late component (Trepel and Racine, 1998; Chapman et al., 1998). Subsequent depotentiation and LTD effects in the contralateral responses were reliably seen only in the late component, so only late component measures are reported for this experiment.

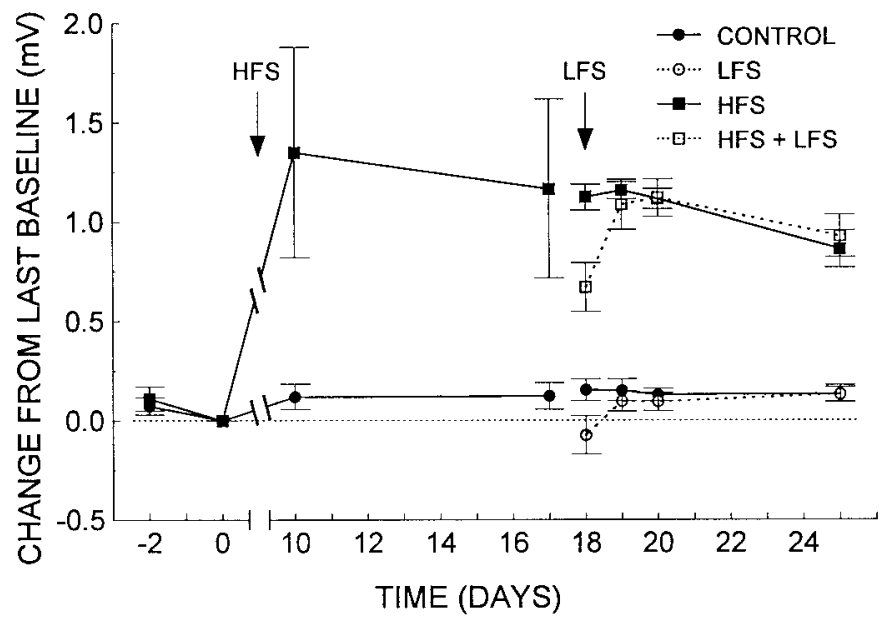

Figure 2. The mean change from baseline amplitude ( \pm SEMs) of the late component in the sensorimotor field potential is shown over days. Stimulation was delivered to the cortex, and the response was recorded in the contralateral homologous site. After $2 \mathrm{~d}$ of baseline tests, the LTP animals received $10 \mathrm{~d}$ of high-frequency stimulation trains (break in $x$-axis). Values indicate the change in the late component amplitude relative to the last baseline I-O test. After the induction of LTP, five of the potentiated animals (HFS $+L F S)$, and four of the control animals $(L F S)$ received low-frequency trains $(1 \mathrm{~Hz}, 15 \mathrm{~min})$. I-O measures were collected daily for $2 \mathrm{~d}$ and again 1 week later to monitor the longevity of these effects. The LTD effect was not significant, and the depotentiation effect decayed within $24 \mathrm{hr}$.

The largest potentiation effects for the late component were observed at intermediate test pulse intensities. At an intensity of $795 \mu \mathrm{A}$, the late component increased by $1.35 \pm 0.26 \mathrm{mV}$ from baseline amplitude, whereas control animals showed a change of only $0.12 \pm 0.06 \mathrm{mV}\left(F_{(1,15)}=16.69 ; p<0.001\right)$. The potentiation decayed by only $16.6 \pm 8.0 \%$ during the following $7 \mathrm{~d}$ (Fig. 2). Responses evoked in the control animals remained stable throughout the experiment.

\section{Depotentiation and LTD}

Low-frequency stimulation delivered $8 \mathrm{~d}$ after LTP induction resulted in a reliable depotentiation of the late component compared to controls, but the earlier components were not markedly affected (Fig. $1 B$ ). The potentiated animals showed a mean late component depotentiation of $42.0 \%$ immediately after lowfrequency stimulation. This depotentiation effect was short-lived, however, and the responses increased back to potentiated levels in $<24$ hr (Fig. 2). Responses in potentiated animals that did not receive low-frequency stimulation were only slightly reduced in amplitude from the level of the previous day. A repeated measures ANOVA performed on the data after low-frequency stimulation showed that the difference between the groups was significant $\left(F_{(1,7)}=202.7 ; p<0.001\right)$. Two of the four animals that were not potentiated showed a transient depression in the late component after low-frequency stimulation, (Figs. $1 C, 2$ ), but this effect was not statistically significant.

\section{Depotentiation of ipsilateral versus contralateral responses}

In the previous experiment, when stimulation was applied to the homologous site in the contralateral hemisphere, the depotentiation effects were significant, but short-lived. The effects were also restricted to the polysynaptic components,. The second experiment was designed to determine if depotentiation might be more 
robust and long-lasting in response to ipsilateral white matter stimulation.

\section{Long-term potentiation}

A $400 \mu \mathrm{A}$ pulse was added to the $\mathrm{I}-\mathrm{O}$ test to increase resolution at the midrange intensities. Maximum LTP effects occurred at low to midrange test pulse intensities after both contralateral (125 $\mu \mathrm{A}, n=2$ of $7 ; 250 \mu \mathrm{A}, n=2$ of 7 ; and $400 \mu \mathrm{A}, n=3$ of 7 ) and ipsilateral $(125 \mu \mathrm{A}, n=1$ of $6 ; 250 \mu \mathrm{A}, n=4$ of 6 ; and $400 \mu \mathrm{A}$, $n=1$ of 6 ) tetanization. Both groups displayed an enhancement in the population spike (Fig. $3 B$ ) and late component (Fig. 3C) amplitudes reflected by significant main effects of session $\left(F_{(1,11)}\right.$ $=90.2, p<0.001 ; F_{(1,11)}=26.25, p<0.001$, respectively). These LTP effects were slightly larger in the contralateral responses than in the ipsilateral responses, but these differences were not statistically significant $\left(F_{(1,11)}=1.85 ; p>0.2 ; F_{(1,11)}=3.55 ; p>0.08\right.$, respectively).

\section{Depotentiation}

Although a few animals showed what appeared to be a stimulation-dependent depotentiation of the early component in the ipsilateral response, this effect was not significant (Fig. 3A, $B$ ). There was also no significant difference between ipsilateral and contralateral measures in the early component measures. The decreases in late component response amplitudes after lowfrequency stimulation in both groups are reflected in a main effect of tetanization $\left(F_{(1,11)}=19.33 ; p<0.002\right)$. As in the first experiment, the low-frequency stimulation produced only a weak and short-lived change in the response amplitude of the contralateral response. The depotentiation was nearly complete, however, in the late component of the ipsilateral response, with amplitudes returning to the baseline levels recorded before LTP was induced (Fig. 3C). The depotentiation effect was still strong $24 \mathrm{hr}$ later. The contralateral response, on the other hand, returned to potentiated levels after $24 \mathrm{hr}$, and analysis of the pre-low-frequency and post-low-frequency stimulation measures, between ipsilateral and contralateral responses, showed a nearly significant interaction effect $\left(F_{(1,11)}=4.16 ; p<0.06\right)$. This experiment confirmed that potentiated responses could be depressed by low-frequency stimulation and showed that these effects were still evident at $24 \mathrm{hr}$.

\section{Long-term depression}

The long-term depression of interhemispherically evoked baseline responses observed in the first experiment was quite weak and short-lived. This experiment was designed to test LTD effects produced by low-frequency stimulation of ipsilateral white matter and to determine if LTD could be more effectively induced by massed or spaced stimulation trains than by delivery of a single low-frequency train. Results showed that the amount of LTD induced depended on whether the animals received single or multiple trains of stimulation (Fig. 4), and this was reflected in a significant main effect of group for both the early $\left(F_{(3,20)}=7.45\right.$; $p<0.002)$ and late $\left(F_{(3,20)}=6.41 ; p<0.004\right)$ component measures. Subsequent comparisons will be pairwise between groups.

\section{LTD induced by a single low-frequency train}

A single LFS train produced a small, nonsignificant depression of the early component (Tukey HSD; $p>0.42$ ) and a statistically reliable depression of the late component (Fig. 4; Tukey HSD; $p<0.001)$ compared to controls. There was a mean decrease of
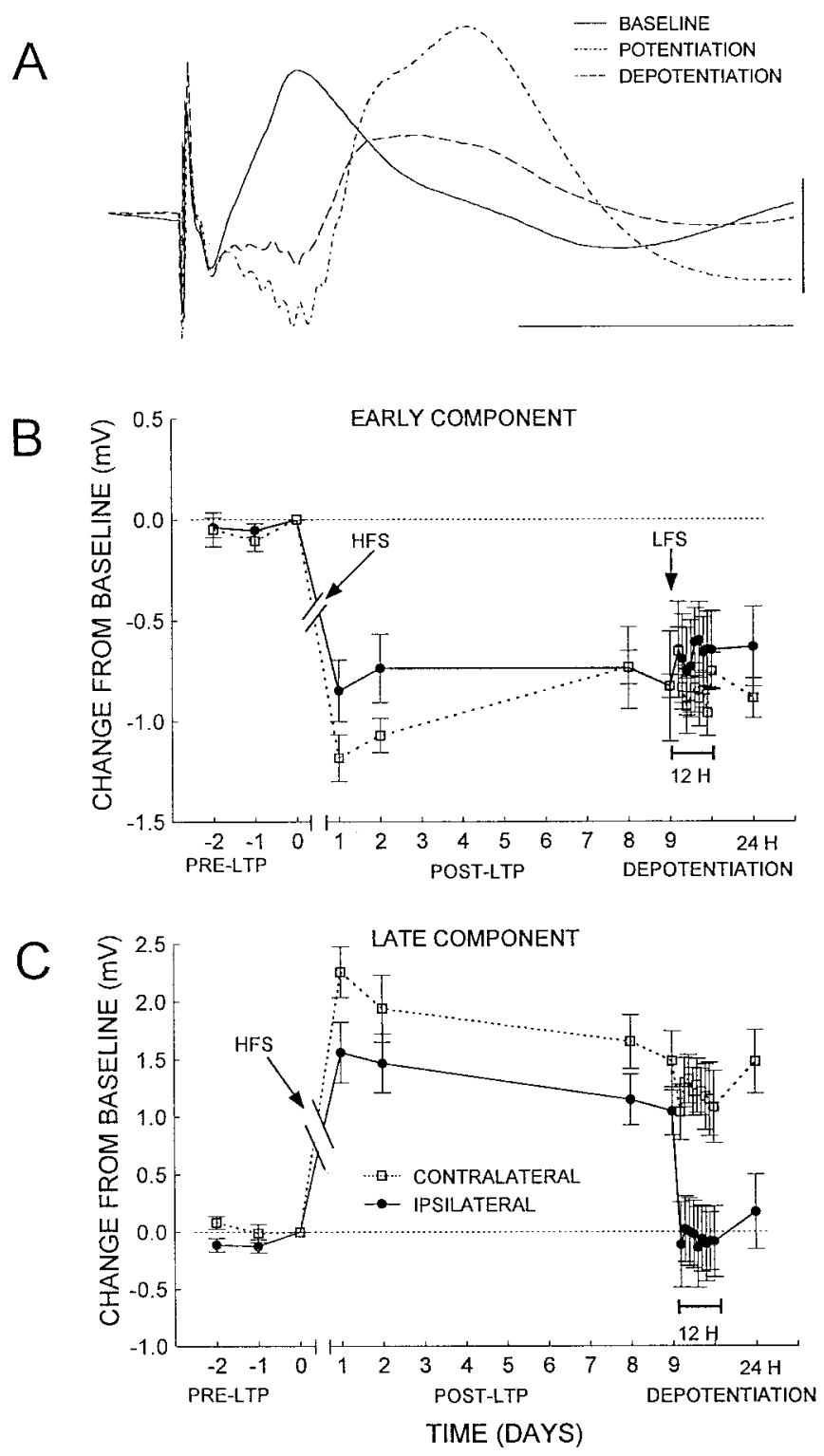

Figure 3. A comparison of depotentiation effects induced in sensorimotor responses by low-frequency stimulation of either the contralateral homologous site or the ipsilateral white matter. $A$, Representative sweeps taken from one animal in the ipsilateral group comparing baseline to potentiated and depotentiated responses. LFS caused a decrease in population spike amplitude and number, as well as a decrease in the amplitude of the late component. Calibration: $1 \mathrm{mV}, 25 \mathrm{msec} . B, C$, The mean change from baseline amplitudes $( \pm$ SEMs $)$ of the early monosynaptic $(B)$ and late polysynaptic $(C)$ components in sensorimotor cortex field potentials are shown here for the contralateral (open squares) and ipsilateral ( filled circles) stimulation groups. Values indicate the change in the late component amplitude relative to the last baseline I-O test. Both population spikes and late components were clearly enhanced after $10 \mathrm{~d}$ of high-frequency stimulation, and these changes persisted with little decay for the next $7 \mathrm{~d}$. Depotentiation was induced by the delivery of a single low-frequency train $(1 \mathrm{~Hz}, 15 \mathrm{sec})$ and is reflected as a decrease in amplitude relative to the pre-LFS measures. These effects were only significant for the late component. Although depotentiated responses were still evident after $24 \mathrm{hr}$ in the ipsilateral group, they had recovered back to the potentiated levels in the contralateral group. Stimulation intensity was $250 \mu \mathrm{A}$. 

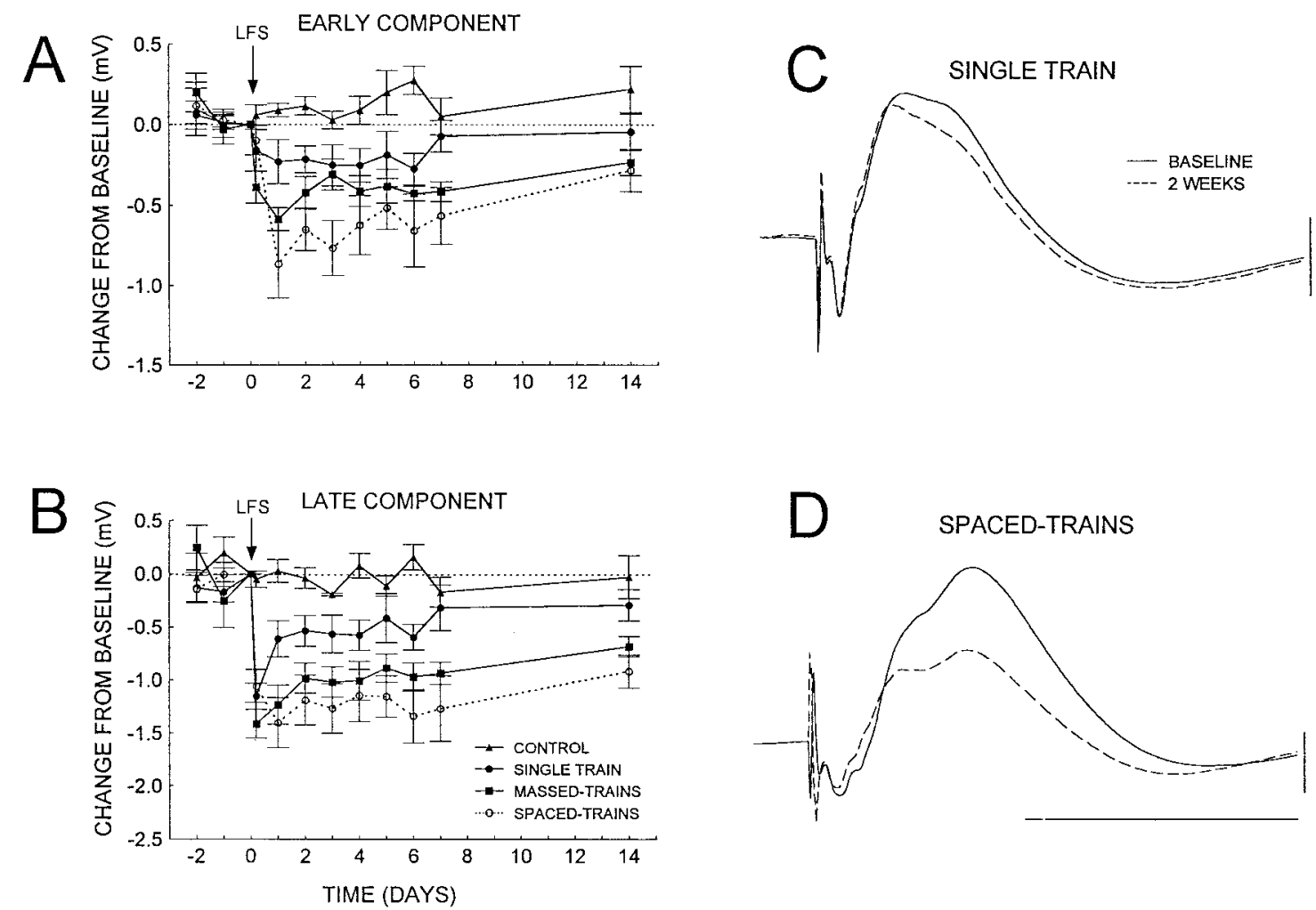

Figure 4. Multiple low-frequency trains induced a larger and longer lasting LTD effect in ipsilaterally evoked sensorimotor cortex responses than did a single train. $A, B$, Changes in the amplitude of the early $(A)$ and the late $(B)$ field potential components in a control group and in three groups receiving different patterns of low-frequency stimulation. After three baseline test sessions, experimental groups received either one train (SINGLE TRAIN) or multiple trains. Multiple-train groups received either 10 trains over $10 \mathrm{hr}($ MASSED-TRAINS) or 10 trains over $10 \mathrm{~d}(S P A C E D-T R A I N S)$. Control animals did not receive low-frequency stimulation. Values indicate the change in the late component amplitude relative to the last baseline I-O test. A substantial LTD effect was found in all experimental groups, and the multiple-train stimulation produced the largest and longest lasting effects. The stimulation intensity was $250 \mu \mathrm{A}$. $C, D$, Representative sweeps from animals in the single-train $(C)$ and spaced-trains $(D)$ LTD groups. The baseline responses are compared to the responses evoked 2 weeks after the induction of LTD. Calibration: $1 \mathrm{mV}, 25 \mathrm{msec}$.

$54.0 \%$ in late component field response amplitudes immediately after low-frequency stimulation. The maximum LTD effect occurred at midrange intensities $(160 \mu \mathrm{A}, n=3$ of $6 ; 250 \mu \mathrm{A}, n=$ 3 of 6$)$. Although the mean response amplitude was still depressed by $29.0 \% 24 \mathrm{hr}$ later, the difference was no longer statistically significant (Tukey HSD; $p>0.13$ ). After 1 and 2 weeks, the decrease in response amplitude was further reduced to 13.0 and $13.7 \%$ respectively.

All six animals exhibited an increase in evoked potential thresholds, such that the stimulus intensity required to evoke a response was greater after LTD induction than during baseline recording. To assess whether or not the LTD effect was associated with neural damage, high-frequency trains were subsequently applied to the white matter to determine if LTP could still be induced. Responses were enhanced by the third day of highfrequency stimulation and reached asymptotic levels after 8 or $9 \mathrm{~d}$ of stimulation (data not shown). There was a tenfold increase in the amplitude of the late component at low to midrange intensities $(160-250 \mu \mathrm{A})$ after LTP induction, indicating that the affected synapses are capable of supporting further plastic changes following LTD induction.

\section{LTD induced by massed, multiple stimulation trains}

Multiple low-frequency stimulation trains delivered on one day produced an LTD effect that was larger than that observed in the single-train group (Fig. 4A,B). Both early and late components were affected. Moreover, the LTD effect was significantly larger at the end of the 10 stimulation trains than they were after the first train for both the early $\left(F_{(9,45)}=8.84 ; p<0.001\right)$ and late $\left(F_{(9,45)}\right.$ $=4.40 ; p<0.001$ ) components (Fig. $5 B, C)$. Maximal depression was observed at low to midrange intensities $(160-250 \mu \mathrm{A})$. Immediately after the LFS, the mean amplitude of the early component was $39.9 \%$ of baseline, which was significantly different from controls (Tukey HSD; $p<0.001$ ). During the first $24 \mathrm{hr}$ and at 7 and $14 \mathrm{~d}$ after conditioning, the decrease in response amplitude decayed to $28.6,20.4$, and $11.7 \%$, respectively, of baseline. Seven days after the LFS, the LTD effect was not quite significantly different from controls (Tukey HSD; $p>0.08$ ) or single session animals (Tukey HSD; $p>0.06$ ).

The late component response amplitudes were decreased by a mean of $76.7 \%$ immediately after the trains (Tukey HSD; $p<$ $0.001)$. After $24 \mathrm{hr}$, response amplitudes were at $47.8 \%$ of baseline levels. Responses showed further recovery 1 and 2 weeks after stimulation to 35.5 and $27.0 \%$ of baseline levels, respectively. The late component LTD effect was still significantly different from controls after 2 weeks (Tukey HSD; $p<0.04$ ).

\section{LTD induced by spaced, multiple stimulation trains}

Multiple low-frequency stimulation trains delivered once per day for $10 \mathrm{~d}$ produced a large LTD effect (Fig. 4; Tukey HSD; $p<$ 0.001). The immediate depression showed somewhat steeper decay rates during each of the first 5 , compared to the second $5 \mathrm{~d}$ (Fig. 5C). Again, the depression was maximal at low to midrange intensities $(160 \mu \mathrm{A})$. Response amplitudes were decreased by 5.6 

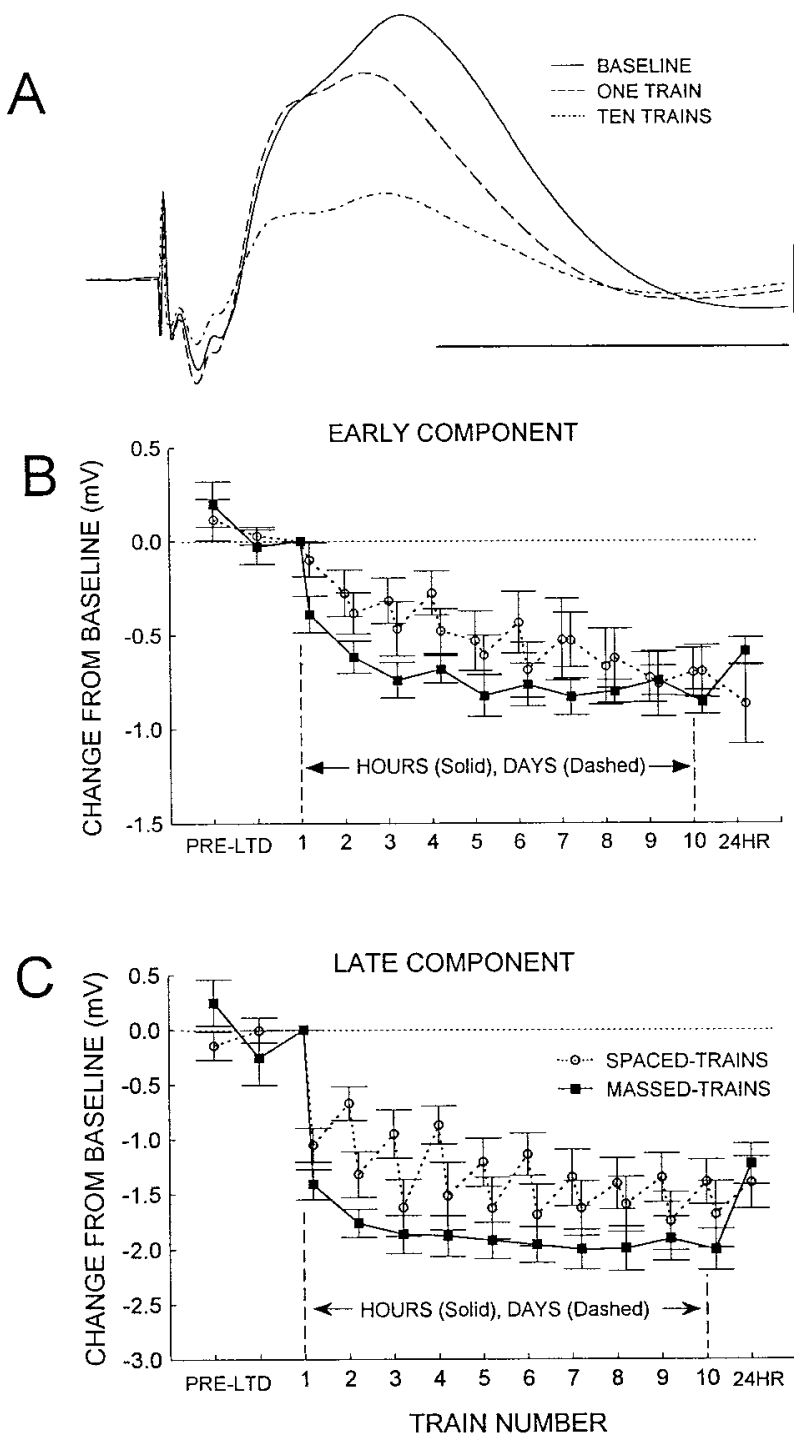

Figure 5. Multiple sessions augment the LTD effect observed after the first session of low-frequency $(1 \mathrm{~Hz}$ for $15 \mathrm{~min}$ ) stimulation. $A$, Representative sweeps from an animal in the spaced-trains group comparing the first session and 10th session LTD effect to the last baseline response. Calibration: $1 \mathrm{mV}, 25 \mathrm{msec} . B, C$, Changes in response amplitudes for the early monosynaptic $(B)$ and longer latency polysynaptic $(C)$ components monitored during LTD induction in the multiple train groups. Trains were delivered either hourly (MASSED-TRAINS) or daily (SPACED$T R A I N S)$. I-O tests were recorded both before and after each train in the spaced trains groups, so that the decay of the LTD effect could be observed for each $24 \mathrm{hr}$ poststimulation period. The final point in the graph shows response amplitudes $24 \mathrm{hr}$ after the last low-frequency train. Similar amounts of LTD were observed for both spaced and massed groups.

and $45.0 \%$ immediately after the first low-frequency train and by 33.5 and $70.2 \%$ immediately after the tenth train for the early and late components, respectively. Both the early $\left(F_{(9,45)}=6.10 ; p<\right.$ $0.001)$ and late $\left(F_{(9,45)}=9.14 ; p<0.001\right)$ component measures showed a significant main effect of session over the LTD induction phase. Although the early component response was still depressed, compared to controls $7 \mathrm{~d}$ after the application of the low-frequency trains (Tukey HSD; $p<0.02$ ), it was no longer significantly different from the depression seen in the single session group. The late component remained significantly de- pressed at 2 weeks compared to both control (Tukey HSD; $p<$ 0.003 ) and single session groups (Tukey HSD; $p<0.04$ ).

\section{DISCUSSION}

Long-term potentiation is difficult to induce in the neocortex in vivo, using stimulation procedures that are effective in subcortical sites (Racine et al., 1994, 1995; for review, see Tsumoto, 1990). Tetanization of the white matter can induce LTP in the neocortex of the awake, freely moving animal, however, as long as the stimulation trains are spaced and repeated (Racine et al., 1995; Trepel and Racine, 1998). Using a similar preparation, we show here that LTP can also be induced by stimulation of the homologous site in the contralateral neocortex. Furthermore, we have shown that low-frequency stimulation can induce a depression of potentiated responses (i.e., depotentiation) similar to that reported previously in subcortical sites (Bashir and Collingridge, 1994) and in neocortical slice preparations (Artola and Singer, 1993; Kirkwood and Bear, 1994a). We have also demonstrated that long-term depression effects can be induced in naive animals. Finally, we have found larger and longer-lasting LTD effects when multiple low-frequency trains are applied to ipsilateral white matter. These results indicate that neocortical LTD is reliably induced, long-lasting, and dependent on the number of stimulation trains.

The evoked potentials observed in these experiments are similar to those reported previously (Vanderwolf et al., 1987; Chapman et al., 1998). The early component of the field response evoked by ipsilateral white matter stimulation was shown by Chapman et al. (1998) to consist of both monosynaptic EPSPs and population spikes, whereas the late component is driven polysynaptically. The morphology and plasticity of contralaterally evoked responses were similar to responses evoked ipsilaterally, but it remains to be determined if they are generated by the same layer $\mathrm{V}$ substrates known to underlie the salient components of ipsilaterally evoked responses (Chapman et al., 1998).

Depotentiation effects were larger and longer-lasting when low-frequency stimulation was delivered to the ipsilateral white matter than when it was delivered to the contralateral cortical site. Responses remained depressed for at least $24 \mathrm{hr}$ after ipsilateral stimulation, but decayed back to baseline within $24 \mathrm{hr}$ after contralateral stimulation. The difference might be caused by a stronger activation of afferents by ipsilateral stimulation, but the long-term potentiation effects were similar for groups receiving ipsilateral and contralateral stimulation (Fig. 3). Another possible explanation for the stronger depression effects with ipsilateral stimulation is a greater activation of thalamic and/or neuromodulatory systems that could then feed back onto the sensorimotor cortex. Some of these systems may facilitate induction of LTD or depotentiation.

The LTD effect induced by a single low-frequency train decays rapidly, over hours, whereas LTD induced by multiple stimulation sessions lasts for at least 2 weeks. Multiple stimulation sessions may therefore recruit distinct mechanisms that mediate a longerlasting form of LTD. LTD, like LTP, may consist of multiple components with different decay time-constants (for discussion of multiple components for LTP, see Racine et al., 1983; Krug et al., 1984; Frey et al., 1988; Matthies et al., 1989; Jeffery et al., 1990; Abraham et al., 1993). Both short- and long-term depression effects are also observed in in vitro slice preparations, where a large, initial effect of low-frequency stimulation decays within several minutes, unmasking a more durable but less substantial effect (Dudek and Bear, 1992; Artola and Singer, 1993; Kirkwood 
and Bear, 1994a,b). In vitro responses recorded in the motor and somatosensory cortices (Castro-Alamancos et al., 1995), hippocampus (Mulkey and Malenka, 1992; Dudek and Bear, 1993), and visual cortex (Bröcher et al., 1992) express both long- and short-term depression effects, which are dissociable based on their NMDA receptor dependence and independence, respectively.

Both the massed and spaced multiple-train protocols produced comparable amounts of LTD immediately after stimulation and also showed similar rates of decay during the daily and weekly follow-up I-O measures. The spacing of stimulus trains is therefore not as critical for LTD induction as it is for LTP induction (Trepel and Racine, 1998).

Kirkwood and Bear (1994a) proposed a dual threshold for LTP and LTD induction that is dependent on the degree of NMDA receptor activation and $\mathrm{Ca}^{2+}$ entry. Repetitive $1-3 \mathrm{~Hz}$ stimulation of the Schaffer collaterals induced a depression of synaptic efficacy that lasted for $>1$ hr (Dudek and Bear, 1992, 1993), and this form of LTD requires an increase of postsynaptic $\mathrm{Ca}^{2+}$ during stimulation (Tsumoto, 1990; Mulkey and Malenka, 1992). Ultimately, then, the level of $\mathrm{Ca}^{2+}$ activity may determine whether LTP or LTD will be induced by neural activation (Lisman, 1989; Bröcher et al., 1992; Kirkwood and Bear, 1994b). Furthermore, LTP, LTD and depotentiation in the CA1 region of the hippocampus are all blocked by D-AP-5, whereas only LTP is blocked by 3-(RS)-2-carboxypiperazin-4-yl)-1-phosphonic acid (CPP), suggesting that LTP and LTD are induced by pharmacologically distinct NMDA receptors (Hrabetova and Sacktor, 1997). Metabotropic glutamate receptor-dependent mechanisms have also been shown to contribute to LTD and depotentiation effects (Kato, 1993; Haruta et al., 1994; O’Mara et al., 1995).

Although both early and late components showed reliable depression effects, they were somewhat more robust for the late components, particularly for depotentiation. This late component depression could be mediated by a decreased volley from monosynaptically driven sites or by direct changes within the polysynaptic pathways themselves. If the responses are passively driven by changes in the monosynaptic sites, the failure to find robust monosynaptic depotentiation may simply indicate that our procedures were not sufficiently sensitive to detect those effects. Other manipulations, such as the application of barbiturate anesthetics, have also shown that the depression of polysynaptic responses can be detected more easily than the depression of monosynaptic responses (Chapman et al., 1998). Alternatively, the difference in reliability of the early and late component depression effects may indicate that they are partially independent phenomena. Some portion of the late component LTD and depotentiation effects, for example, might be expressed within the horizontal pathways.

The results of these experiments are consistent with theoretical models of learning and memory that require bidirectional modifications in synaptic efficacy. Most neural network models, however, use symmetrical learning rules, with equivalent rates of increment and decrement of synaptic weights. Our results raise the interesting question of why the nature of neocortical LTP and LTD effects, in chronic preparations, are so dissimilar. In contrast to LTP, LTD reached asymptotic levels rapidly, decayed relatively quickly, and could be induced with a single session of stimulation. Moreover, the LTD effects were most readily induced in the polysynaptic components. Although the in vivo neocortex can support bidirectional synaptic plasticity, the rules governing this plasticity may be biased toward the weakening of horizontal connections that mediate polysynaptic responses.

\section{REFERENCES}

Abraham WC, Mason SE, Demmer J, Williams JM, Richardson CL, Tate WP, Lawlor PA, Dragunow M (1993) Correlations between immediate early gene induction and the persistence of long-term potentiation. Neuroscience 56:717-727.

Abraham WC, Mason-Parker SE, Logan B (1996) Low-frequency stimulation does not readily cause long-term depression of depotentiation in the dentate gyrus of awake rats. Brain Res 722:217-221.

Artola A, Singer W (1993) Long-term depression of excitatory synaptic transmission and its relationship to long-term potentiation. Trends Neurosci 16:80-87.

Barrionuevo G, Schottler F, Lynch G (1980) The effects of low frequency stimulation on control and potentiated synaptic responses in the hippocampus. Life Sciences 27:2385-2391.

Bashir ZI, Collingridge GL (1994) An investigation of depotentiation of long-term potentiation in the CA1 region of the hippocampus. Exp Brain Res 100:437-443.

Beiko J, Cain DP (1998) The effect of water maze spatial training on posterior parietal cortex transcallosal evoked field potentials in the rat. Cereb Cortex 8:404-414.

Bliss TVP, Collingridge GL (1993) A synaptic model of memory: longterm potentiation in the hippocampus. Nature 361:31-39.

Bliss TVP, Lomo TJ (1973) Long-lasting potentiation of synaptic transmission in the dentate area of the anesthetized rabbit following stimulation of the perforant path. J Physiol (Lond) 232:331-356.

Bröcher S, Artola A, Singer W (1992) Intracellular injection of Ca2+ chelators blocks induction of long-term depression in rat visual cortex. Proc Natl Acad Sci USA 9:123-127.

Brown TH, Kairiss EW, Keenan CL (1990) Hebbian synapses: biophysical mechanisms and algorithms. Annu Rev Neurosci 13:475-511.

Burette F, Jay TM, Laroche S (1997) Reversal of LTP in the hippocampal afferent fiber system to the prefrontal cortex in vivo with lowfrequency patterns of stimulation that do not produce LTD. J Neurophysiol 78:1155-60.

Castro-Alamancos MA, Donoghue JP, Connors BW (1995) Different forms of synaptic plasticity in somatosensory and motor areas of the neocortex. J Neurosci 15:5324-5333.

Chapman CA, Trepel C, Ivanco TL, Froc DJ, Wilson K, Racine RJ (1998) Changes in field potentials and membrane currents in rat sensorimotor cortex following repeated tetanization of the corpus callosum in vivo. Cereb Cortex 8:730-742.

Doyle CA, Cullen WK, Rowan MJ, Anwyl R (1997) Low-frequency stimulation induces homosynaptic depotentiation but not long-term depression of synaptic transmission in the adult anaesthetized and awake hippocampus in vivo. Neuroscience 77:75-85.

Dudek SM, Bear MF (1992) Homosynaptic long-term depression in area CA1 of hippocampus and effects of $N$-Methyl-D-aspartate receptor blockade. Proc Natl Acad Sci USA 79:4363-4367.

Dudek SM, Bear MF (1993) Bidirectional long-term modification of synaptic effectiveness in the adult and immature hippocampus. J Neurosci 13:2910-2918.

Errington ML, Bliss TVP, Richter-Levin G, Yenk K, Doyère V, Laroche $\mathrm{S}$ (1995) Stimulation at 1-5 Hz does not produce long-term depression or depotentiation in the hippocampus of the adult rat in vivo. J Neurophysiol 74:1793-1799.

Frey U, Krug M, Reymann KG, Matthies H (1988) Anisomycin, an inhibitor of protein synthesis, blocks late phases of LTP phenomena in the hippocampal CA1 region in vitro. Brain Res 452:57-65.

Froc DJ, Racine RJ (1995) Transcallosal induction of long-term potentiation and depotentiation in the frontal and visual cortices of the awake rat. Soc Neurosci Abstr 21:1812.

Froc DJ, Trepel C, Racine RJ (1996) Induction of neocortical depotentiation and long-term depression in the adult behaving rat. Soc Neurosci Abstr 22:1504.

Haruta H, Kamishita T, Hicks TP, Takahashi MP, Tsumoto T (1994) Induction of LTD but not

LTP through metabotropic glutamate receptors in visual cortex. NeuroReport 5:1829-32.

Hebb DO (1949) The organization of behavior, New York: Wiley.

Heynen AJ, Abraham WC, Bear MF (1996) Bidirectional modification of CA1 synapses in the adult hippocampus in vivo. Nature 381:163-166.

Hrabetova S, Sacktor TC (1997) Long-term potentiation and long-term depression are induced through pharmacologically distinct NMDA receptors. Neurosci Lett 226:107-110.

Jeffery KJ, Abraham WC, Dragunow M, Mason, SE (1990) Induction of 
Fos-like immunoreactivity and the maintenance of long-term potentiation in the dentate gyrus of unanesthetized rats. Mol Brain Res 8:267-274.

Kato N (1993) Dependence of long-term depression on postsynaptic metabotropic glutamate receptors in visual cortex. Proc Natl Acad Sci UDA 90:3650-3654.

Kirkwood A, Bear MF (1994a) Hebbian synapses in visual cortex. J Neurosci 14:1634-1645.

Kirkwood A, Bear MF (1994b) Homosynaptic long-term depression in the visual cortex. J Neurosci 14:3403-3412.

Krug M, Lossner B, Ott T (1984) Anisomycin blocks the late phase of long-term potentiation in the dentate gyrus of freely moving rats. Brain Res Bull 13:39-42.

Lisman J (1989) A mechanism for the Hebb and the anti-Hebb processes underlying learning and memory. Proc Nat Acad Sci USA 86:9574-9578.

Manahan-Vaughan D (1997) Group 1 and 2 metabotropic glutamate receptors play differential roles in hippocampal long-term depression and long-term potentiation in freely moving rats. J Neurosci 17:3303-3311.

Matthies H, Frey U, Reymann K, Krug M, Jork R, Schroeder H (1989) Different mechanisms and multiple stages of LTP. Adv Exp Med Biol 268:359-68.

Mulkey RM, Malenka RC (1992) Mechanisms underlying induction of homosynaptic long-term depression in the area CA1 of the hippocampus. Neuron 9:967-975.

O'Mara SM, Rowan MJ, Anwyl R (1995) Dantrolene inhibits long-term depression and depotentiation of synaptic transmission in the rat dentate gyrus. Neuroscience 68:621-624.

Paxinos G, Watson C (1997) The rat brain in stereotaxic coordinates, Ed 3. San Diego, CA, Academic Press.
Racine RJ, Milgram NW, Hafner S (1983) Long-term potentiation phenomena in the rat limbic forebrain. Brain Res 260:217-231.

Racine RJ, Teskey GC, Wilson D, Seidlitz E, Milgram NW (1994) Post-activation potentiation and depression in the neocortex of the rat: II. Chronic preparations. Brain Res 637:83-96.

Racine RJ, Chapman CA, Trepel C, Teskey GC, Milgram NW (1995) Post-activation potentiation in the neocortex: IV. Multiple sessions required for induction of long-term potentiation in the chronic preparation. Brain Res 702:87-93.

Staubli, U, Lynch G (1990) Stable depression of potentiated synaptic responses in the hippocampus with $1-5 \mathrm{~Hz}$ stimulation. Brain Res 513:113-118.

Staubli U, Scafidi J (1997) Studies on long-term depression in area CA1 of the anesthetized and freely moving rat. J Neurosci 17:4820-4828.

Thiels E, Barrioneuvo G, Berger TW (1994) Excitatory stimulation during postsynaptic inhibition induces long-term depression in hippocampus in vivo. J Neurophysiol 72:3009-3016.

Trepel C, Racine RJ (1998) Long-term potentiation in the neocortex of the adult, freely moving rat. Cereb Cortex 8:719-729.

Tsumoto T (1990) Long-term potentiation and depression in the cerebral neocortex. Japanese. J Physiol (Lond) 40:573-593.

Tsumoto T (1992) Long-term potentiation and long-term depression in the neocortex. Prog Neurobiol 39:209-228.

Tsumoto T, Suda K (1979) Cross-depression: an electrophysiological manifestation of binocular competition in the developing visual cortex. Brain Res 168:190-194.

Vanderwolf CH, Harvey GC, Leung LW (1987) Transcallosal evoked potentials in relation to behavior in the rat: effects of atropine, $p$-chlorophenylalanine, reserpine, scopolamine and trifluoperazine. Behav Brain Res 25:31-48. 